\title{
Stimulating Technology-Based Start-Ups: Entrepreneurship Initiatives by University
}

\author{
Noorlizawati Abd Rahim, Zainai B. Mohamed, Astuty Amrin \\ Razak School of Engineering \& Advanced Technology, University Teknologi Malaysia, Kuala Lumpur, 54100, Malaysia
}

\begin{abstract}
2016 Research Leap/ Inovatus Services Ltd. All rights reserved.

DOI: $10.18775 / \mathrm{jibrm} .1849-8558.2015 .16 .3002$ URL: http://dx.doi.org/10.18775/jibrm.18498558.2015 .16 .3002

Keywords:

This paper aims to explore to what extent university's role in providing supportive infrastructure contributes to venture creation. Specifically, best practices in stimulating technology-based start-ups have not been widely discussed in the context of developing country. Although the previous study has explored this from a management perspective, this paper provides further insights on how academic entrepreneurship or entrepreneurial activity in a university can be increased through various initiatives. Considering Universiti Teknologi Malaysia (UTM) as a case study, findings identify that collaborative business incubation and entrepreneurship education for academic entrepreneurs as evidence of practices that stimulates commercialization of university-invented technologies as well as develops academic entrepreneurs amongst research scientists.
\end{abstract}

Academic Entrepreneurship

Research Commercialization

Technology Transfer Office

Technology-based Start-ups

\section{Introduction}

In the age of the Internet where barriers to international trade are non-existing, leading countries are tapping the opportunity of a borderless world, embracing venture creation that utilizes knowledge spawned from research universities. In the United States, big names like Google, Facebook and LinkedIn are among the examples of venture in the borderless world that utilize most of their knowledge resources from Stanford University (Eesley \& Miller, 2012). The rise of the entrepreneurial university like Stanford sets a good role model of university's transition from its traditional role in education and research to a contributor for economic growth via innovation and knowledge-based entrepreneurship (Audretsch, 2009). Eesly and Miller (2012) studying the economic impact of innovation and entrepreneurship found that there are at least 400 thousand active companies originated from Stanford University since the 1930s. Such impressive statistics for one university led the diffusion of entrepreneurial university model throughout the US university system (Ziedonis, 2004). As a result, universities worldwide are adopting similar approach and best practices to promote technology transfer (Swamidass, 2013) such as linkage with industry (Rast et al., 2012, Etzkowitz, 1998), creation of technology transfer office with skilled personnel (Siegel et al.,
2008), and university start-ups policies (Degroof et al., 2004) and this phonemenon has been widely discussed in the literature.

However, it can be argued that the effectiveness of such implementation and the impact they bring to different economic context, particularly, in the Asian countries, are bounded by differences in entrepreneurial environment, culture and mindset. Indeed, there is limited evidence in the literature that explores to what extent university's role in providing supportive infrastructure contributes to venture creation in the developing countries. This paper aims to contribute to a better understanding of the institutional role towards the development of business ventures based on university-invented technologies. Specifically, this preliminary study seeks to answer the following research question:

What are the initiatives undertaken by the university to stimulate academic entrepreneurship and research commercialization?

Based on a case study approach by Eisenhardt (1989), a research university in Malaysia, Universiti Teknologi Malaysia (UTM) is selected, and data were sourced from archival records to review entrepreneurship infrastructure that the University has been established and initiatives that it has been undertaken. 
In Malaysia, universities have historically been perceived merely as centers of education. In the early 90 s, universities have started to intensify research and development (R\&D) activities given the emphasis by the Government for universities to produce technological knowledge (Ramli et al., 2013). Upon the implementation of the National Higher Education Plan (20072010), a transformation was initiated, the universities were then viewed as engines of economic growth via commercialization of intellectual property (IP) as well as through technology transfer into the industrial sector. Accordingly, there has been a growing interest in studies pertaining to the commercialization of research. Considering Malaysia as the context of research, much of the literature has been focused on understanding factors that impede the progress of technology transfer. For example, Tayebeh (2013), identified factors affecting the commercialization rate are due to limited availability of finance and potential licensee, lack of entrepreneurial orientation amongst the researcher and the role of technology transfer office. Another study (Abdulahad, 2013) pointed out factors affecting the commercialization process include university's policy, university-industry relationship, and market-driven innovation. Low (2011), on the other hand, investigated the impeding factors from the perspective of Theory of Planned Behavior, which reveals that the discouraging commercializing rate is also affected by the perception of feasibility amongst researchers. Similarities between these studies are the common factors on the inadequacy of infrastructure support and initiatives by the university to facilitate the technology transfer as well as to develop the entrepreneurial culture. Despite these claims, there has been ongoing improvement undertaken by the University to rectify the issues. This study seeks to fill the literature gap by exploring to what extent university's role in providing supportive infrastructure contributes to venture creation and how academic entrepreneurship or entrepreneurial activity in the university can be increased through various initiatives.

\section{Entrepreneurship Infrastructure: A Case Study of UTM}

Established in 1972 as a teaching university, to date, Universiti Teknologi Malaysia (UTM) is one of the premier Research University in Malaysia, with a total number of 25,172 students, $55 \%$ of which are postgraduate students. Focusing on engineering and technical studies, there are 13 main faculties and five graduate schools with a total number of 1244 academic staff members (UTM, 2014). The university's mission is to develop human capital and innovative technologies that will contribute to the nation's wealth (UTM Annual Report, 2012). Regarding human capital, the university aims to produce graduates equipped with entrepreneurial mindsets who are capable to lead and create innovative industries by improving its teaching and learning methodology. On the other hand, it is through academic entrepreneurship in which research, development, and commercialization activities are streamlined together, that innovative technologies originating from research can be transferred from university to the consumer market. In this sense, the university strives to nurture its own assets, so-called academic entrepreneurs, faculty research members who possess the entrepreneurial capacity and put considerable entrepreneurial efforts to commercialize their research results.

In achieving this entrepreneurial mission, the University has established a strategic governance structure (Figure 1) to coordinate various stakeholders for research, development, innovation, commercialization and entrepreneurship. A university's technology transfer route comprising sequential activities is managed by cooperation networks of three main group of stakeholders which are Research Faculties, Research Alliances and Research Management Centre grouped for the first stage, Innovation and Commercialization Centre (ICC) and UTM Holdings for the subsequent stages. Mechanisms of how this structure drives research, development, and commercialization from management perspectives have been discussed by Aziz et al. (2011). Building on this initial stream of work, this study seeks to provide further insights as from implementation viewpoint, on how such entrepreneurship infrastructure and its initiatives develop academic entrepreneur and stimulate venture creation based on university-invented technologies.

The effort to commercialize research outcomes has already started back in the early 90s through a university's entity called Biro Inovasi Perundingan (Bureau of Innovation \& Consultancy, BIP). There were few commercialization successes during this era although the effort was greatly placed on inventors and researchers themselves due to the inadequacy of BIP's staff. Recently, BIP is reengineered into UTM Innovation and Commercialization Centre, ICC (2010), with a clear focus to facilitate commercialization of university's research outputs. Despite its embryonic nature, the ICC has proven its capability to serve as a platform to educate and train academic entrepreneurs as well as to market the university research outputs. According to a source from Ministry of Education (Aziz et al., 2011), UTM was ranked as the first with the highest total numbers of intellectual property for the year 2008, leading the other four primary research universities in Malaysia (Table 1). To date, the status of the intellectual property for the UTM is as depicted in Table 2. In general, UTM's academic entrepreneurs commercialize their research outputs in the form of copyright, patents, trademarks, industrial design and layout design of integrated circuit. Nonetheless, they are not bound with these mechanisms alone as they are also encouraged to commercialize other intellectual assets such as explicit codified knowledge, manuals, best practices, databases, codified $\mathrm{R} \& \mathrm{D}$ research, processes, reports and brand names (ICC, 2015).

Table 1: Status of Intellectual Property for primary research universities in Malaysia (2008)

\begin{tabular}{lccccc}
\hline University & Patent & $\begin{array}{c}\text { Trade } \\
\text { mark }\end{array}$ & $\begin{array}{c}\text { Total } \\
\text { commercialised } \\
\text { product }\end{array}$ & $\begin{array}{c}\text { Total R\&D with } \\
\text { Potential } \\
\text { for } \\
\text { commercialised } \\
\text { Product }\end{array}$ & $\begin{array}{c}\text { Total } \\
\text { no. } \\
\text { of IP }\end{array}$ \\
\hline Universiti Teknologi Malaysia (UTM) & 9 & 28 & 6 & 110 & 153 \\
Universiti Putra Malaysia (UPM) & 12 & 27 & 16 & 15 & 70 \\
Universiti Kebangsaan Malaysia(UKM) & 3 & 20 & 0 & 33 & 56 \\
Universiti Malaya (UM) & 0 & 11 & 3 & 31 & 45 \\
Universiti Sains Malaysia (USM) & 11 & 4 & 15 & 9 & 39 \\
\hline
\end{tabular}


Table 2: Status of UTM Intellectual Property (As of Nov 2014)

\begin{tabular}{lc}
\hline Intellectual Property Category & Total \\
\hline Patent applications & 795 \\
Patent granted & 140 \\
Utility innovation application & 23 \\
Utility innovation granted & 3 \\
Industrial design & 16 \\
Trademark & 55 \\
Copyright & 2830 \\
Layout design off integrated circuit & 14 \\
TOTAL & 3876 \\
\hline
\end{tabular}

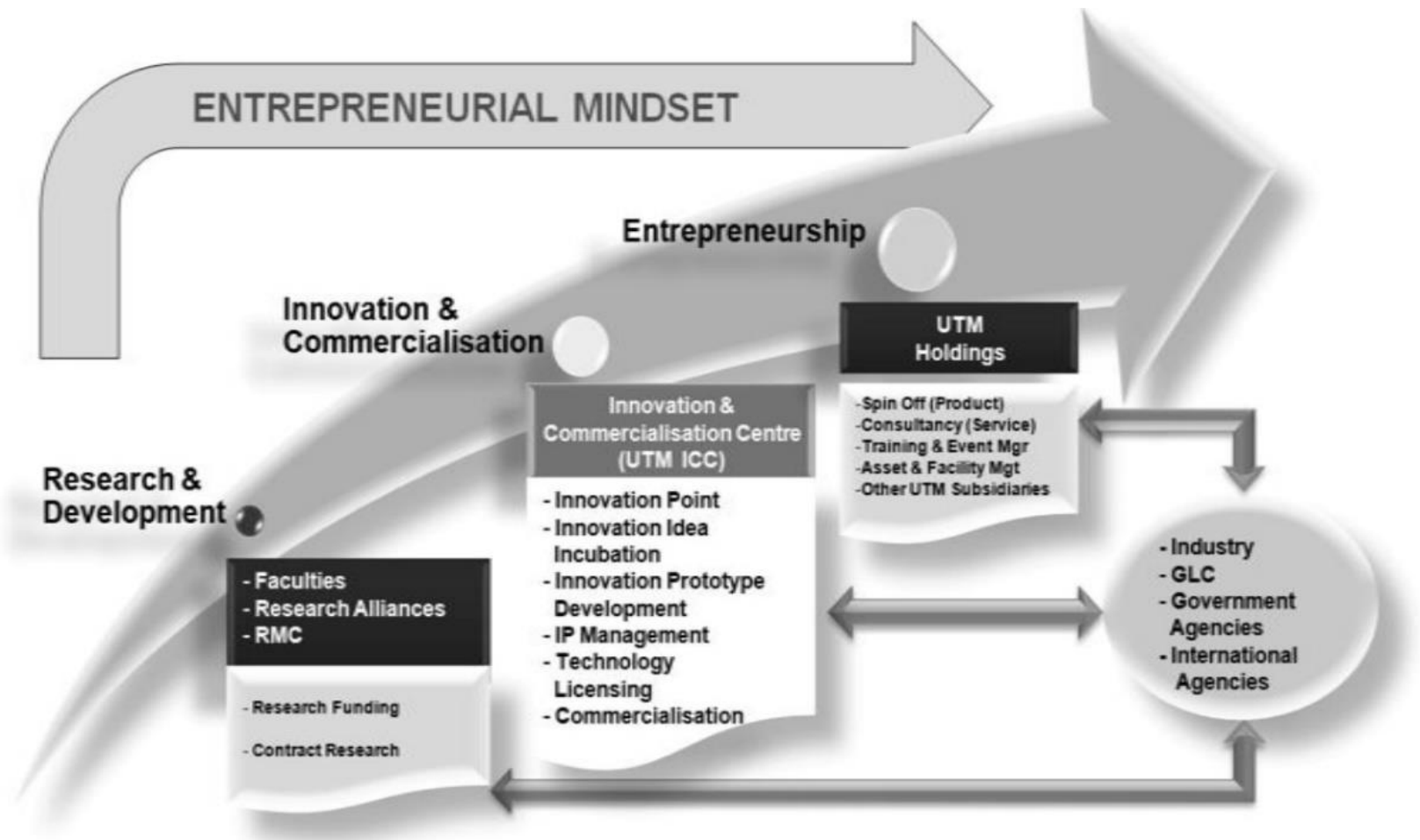

Figure 1: UTM's strategic governance structure to drive technology transfer. (Adopted from ICC Deputy Director

Presentation in Funding Talk, 2015)

\section{Entrepreneurship Initiatives}

3.1 Collaborative Business Incubation Program

The Universiti Teknologi Malaysia (UTM) through its commercialization entity, BIP/ICC has been collaborating with a government agency, Malaysian Technology Development Corporation (MTDC) in a business incubation program called UTM-MTDC Symbiosis. This collaborative effort is geared towards the incubation and formation of start-up companies based on university invented-technologies. The university serves as a technology provider through which ICC will conduct screening process to select an intellectual property from research results that are both innovative and commercially viable. On the other hand, MTDC, which is entrusted to manage government fund for commercialization purpose, will recruit potential entrepreneurs amongst university graduates who will then undergo a threestages training, starting from induction to the selected technologies, concept of marketing, market development, preparation of business plan and towards an establishment of new ventures. MTDC, ICC, and the technology inventors will then work synchronously to transfer all related IPs, ensuring a smooth process of production and marketing by the start-up company. Also, the selected entrepreneur who will eventually launch the technology start-up will be provided with funding scheme, incubation services, office space and business consultations by MTDC. As the technology provider, the university will get monetary returns in terms of licensing fee and royalties. This collaborative business incubation program has been successfully formed ten start-up companies based on university-invented technology (Table 3). Indeed, by matching trained entrepreneurs with innovative technology from the local university, such synergy effort fulfill both government and university vision of contributing to nation's wealth via entrepreneurship.

Table 3: Start-up companies based on university-invented technology (Source: ICC, UTM 2011)

\begin{tabular}{ll}
\hline Spin-off company & University-Invented Technology Commercialised \\
\hline Bioswitch Technologies Sdn. Bhd. & Active Packaging Using A Smart Bio-switch Concept \\
E Elements Technology Sdn. Bhd. & Advance Thermal Control System (ATCS) for Building Air Conditioning Plant \\
Gigalink Solutions Sdn. Bhd. & Antenna Array at 2.4GhZ for point-to-point Communication \\
HQ Nutraceuticals Sdn. Bhd & Pineapple Fiber-based Products for Nutraceuticals \\
Membrane Technology Sdn. Bhd. & Advanced Reverse Osmosis Membrane System \\
Microclear Sdn. Bhd. & Microclear for Coloured Waste Industry \\
Photo Laser Grammetry Sdn. Bhd. & 3D Based Surveillance System \\
& Nanocrystiline Nickel Plating Directly on Aluminium by High Speed \\
Maxglaze Sdn. Bhd. & Electroforming \\
Sono Engineering Sdn Bhd & Novel Medical Device: Ultrasound Sonoimprometer \\
WCC Telco Sdn. Bhd & RF Front End System for Wireless LAN Point-to-Point Link \\
\hline
\end{tabular}

In evaluating the effectiveness of this initiative from venture creation perspective, Chan and Lau (2005) proposed an assessment framework that provides insight into the extent to which technology incubator will benefit the start-up company in terms of consulting services, public image, networking, costing and funding. Provision of legal, technical and business consultation as additional services by MTDC, together with the 
availability of funding sources, partnership opportunity and other subsidies for cost reduction evidently benefit the start-up founders, particularly during the early stage. From an academic entrepreneurship viewpoint, the primary role of technology inventor as a research faculty member will not be in conflict with subsequent business-related tasks (Jain et al., 2009) for growth and sustainability as the start-up will be managed by a trained graduate entrepreneur. In this sense, the role of researcher as an academic entrepreneur is heavily placed on the discovery and identification of technological opportunity, exploitation of commercial opportunity and development of technological product (Rahim et al., 2015). Furthermore, the common perception that scientists are technical-oriented (Wright et al., 2007, Franklin et al., 2001, Venkataraman et al., 1990) and unfit to run business due to skills (Franklin et al., 2001) and social capital (Wright et al., 2007) inadequacy can be resolved through this symbiosis program.

\subsection{Entrepreneurship Education for Academic Entrepreneurs}

Literature has been suggesting the relationship of entrepreneurship education as a precursor of entrepreneurial intention (Bae et al., 2014) that may result in entrepreneurial mindset (Mohamed Z. B., 2013) and activity (Raposo \& Do Paço, 2011). Prodan and Drnovsek (2010) suggest that although individual's entrepreneurial self-efficacy can be influenced by entrepreneurship education, courses and seminars for researchers are still limited especially at technical faculties. In the case of UTM, the ICC has been organizing innovation, business and entrepreneurship program specifically tailored to the needs of potential academic entrepreneurs ranging from senior researchers, researcher to doctoral students. In addition to in-house training, ICC has been collaborating with Stanford Research Institute (SRI International), a non-profit research institute based in Silicon Valley, in sharing SRI's commercialization expertise as well as in bringing UTM's innovation to the international marketplace. For example, a three-year program called UTM-SRI International Innovation Commercialization Readiness Program was launched in 2010 to enhance entrepreneurial culture amongst researchers. The program has adopted multiple approaches from briefings, hands-on practices, real-life experiences as well as individual mentoring in developing academic entrepreneurs amongst UTM researchers. This includes a complete training of familiarization on licensing plan and business model, developing own venture plan, pitching value proposition in venture-capital-like session, visits to Silicon Valley ecosystem and feedback consultation by its experts. In addition, UTM spin-off CEOs were given the opportunity to undertake a CEO training which shares valuable Silicon Valley experiences in establishing start-ups and running a business. Altogether, such design of entrepreneurship education and its execution through experiential learning (Bliemel, 2014) indeed help to build the mindset of researchers to think and act like real entrepreneurs. Furthermore, Mohamed (2013) remarked that 'entrepreneurship education is not learning about entrepreneurship, but learning through entrepreneurship', suggesting that entrepreneurial mindset could be developed through the implementation of entrepreneurship education that emphasizes experiential learning, which is similar to UTM-SRI initiatives. Lessons learned through this program, UTM further strengthen its commercialization strategy, moving into marketdriven R\&D activities that emphasize the need for every research to commence based on industry demands (The Star, February 25, 2013). This initiative has not only provided valuable training to potential academic entrepreneur but, SRI as the program collaborator is also facilitating UTM to commercialize a total of 24 IPs in Silicon Valley.

\section{Conclusion}

Despite the claims that inadequacy of infrastructure support and initiatives have been the impeding factors to research commercialization, considerable infrastructural investment and efforts taken by the university to rectify the issues. Indeed, findings identify that collaborative business incubation and entrepreneurship education for academic entrepreneurs as evidence of practices that stimulates commercialization of university-invented technologies as well as develops academic entrepreneurs amongst research scientists. Moving forward, this study proposes two recommendations that can be withdrawn from this initial observation. First, although there is evidence that initiatives undertaken by university stimulate the venture creation, the outcomes remains as small extent in relative to the organization size and its potential capability. Perhaps, future studies could investigate from an individual perspective to understand how the differences of person characteristics, in terms of entrepreneurial capacity and entrepreneurial effort of university researcher to become academic entrepreneur could be affected by the institutional support. Second, it is practically recommended that for an environment with weak entrepreneurial culture, entrepreneurship education should not wait until higher education, but it should start as early as possible so that entrepreneurial mindset, skills and attitude are developed from young age (European Commission, 2004).

\section{References}

- Abdulahad B. M. (2013). An Exploratory Study on University Teknologi Malaysia's Innovation towards Commercialization. Master Dissertation, Universiti Teknologi Malaysia, Skudai.

- Aziz, K., Harris, H., \& Norhashim, H. (2011). University research, development \& commercialization management: a Malaysian best practice case study. World Review of Business Research, 1(2), 179192.

- $\quad$ Bae, T. J., Qian, S., Miao, C., \& Fiet, J. O. (2014). The Relationship between Entrepreneurship Education and Entrepreneurial Intentions: A Meta - Analytic Review. Entrepreneurship Theory and Practice, 38(2), 217-254, CrossRef

- Bliemel, M. J. (2014). Getting entrepreneurship education out of the classroom and into students' heads. Entrepreneurship Research Journal, 4(2), 237-260.

- Chan, K. F., \& Lau, T. (2005). Assessing technology incubator programs in the science park: the good, the bad and the ugly. Technovation, 25(10), 1215-1228, CrossRef

- Degroof, J. J., \& Roberts, E. B. (2004). Overcoming weak entrepreneurial infrastructures for academic spin-off ventures. The Journal of Technology Transfer, 29(3-4), 327-352, CrossRef

- Eesley, C. E., \& Miller, W. F. (2012). Impact: Stanford University's Economic Impact via Innovation and Entrepreneurship. Available at SSRN 2227460. 
- Eisenhardt, K. M. (1989). Building theories from case study research. Academy of management review, 14(4), 532-550, $\underline{\text { CrossRef, }}$ CrossRef

- Etzkowitz, H. (1998). The norms of entrepreneurial science: cognitive effects of the new university-industry linkages. Research policy, 27(8), 823-833, $\underline{\text { CrossRef }}$

- European Commission (2004), "Education for entrepreneurship: Making progress in promoting entrepreneurial attitudes and skills through Primary and Secondary education", European Commission, February. Retrieved June 2015 from Retrieved June 22, 2015 from http://ec.europa.eu/enterprise/policies/sme/files/support_measures/tra ining_education/doc/entrepreneurship_education_final_en.pdf

- Franklin, S. J., Wright, M., \& Lockett, A. (2001). Academic and surrogate entrepreneurs in university spin-out companies. The Journal of Technology Transfer, 26(1-2), 127-141, CrossRef

- ICC (2015). Facts and Figures. Malaysia. Retrieved June 22, 2015 from http://icc.utm.my/

- Jain, S., George, G., \& Maltarich, M. (2009). Academics or entrepreneurs? Investigating role identity modification of university scientists involved in commercialization activity. Research Policy, 38(6), 922-935, CrossRef

- Low H. H. (2011). Drivers Affecting the Perception of Feasibility Towards Commercialization of Universities' Research and Development Activities. Doctor Philosophy, Universiti Teknologi Malaysia, Skudai.

- Mohamed, Z. B. (2013). Entrepreneurship Education: Learning Through Education. Proceedings of the 2013 Social Enterprise For Economic Development. 10 December 2013. Kuala Lumpur, Malaysia.

- New approach in UTM's innovations. (2013, February 25).The Star. Retrieved June 25, 2015 from http://www.thestar.com.my

- Prodan, I., \& Drnovsek, M. (2010). Conceptualizing academicentrepreneurial intentions: An empirical test. Technovation, 30(5), 332-347, CrossRef

- Rahim, N. A., Mohamed, Z. B., \& Amrin, A. (2015). Commercialization of Emerging Technology: The Role of Academic Entrepreneur. Procedia-Social and Behavioral Sciences, 169, 53-60, $\underline{\text { CrossRef }}$

- $\quad \overline{R a m l i, ~ N ., ~ Z a i n o l, ~ Z . ~ A ., ~ A z i z, ~ J . ~ A ., ~ A l i, ~ H . ~ M ., ~ H a s s i m, ~ J ., ~ H u s s e i n, ~}$ W. M. H. W., ... \& Yaakob, N. I. (2013). The Concept of Research University: The Implementation in the Context of Malaysian University System. Asian Social Science, 9(5), p307, CrossRef

- Raposo, M., \& Do Paço, A. (2011). Entrepreneurship education: Relationship between education and entrepreneurial activity. Psicothema, 23(3), 453-457.

- Rast, S., Khabiri, N., \& Senin, A. A. (2012). Evaluation framework for assessing university-industry collaborative research and technological initiative. Procedia-Social and Behavioral Sciences, 40, 410-416, CrossRef

- $\quad$ Siegel, D., Wright, M., Chapple, W., \& Lockett, A. (2008). Assessing the relative performance of university technology transfer in the US and UK: A stochastic distance function approach. Econ. Innov. New Techn., 17(7-8), 717-729, $\underline{\text { CrossRef }}$

- Swamidass, P. M. (2013). University startups as a commercialization alternative: lessons from three contrasting case studies. The Journal of Technology Transfer, 38(6), 788-808, CrossRef

- Tayebeh K. (2013). The Factors to Improve Commercialization Rate: A Case Study in UTM. Master, Universiti Teknologi Malaysia, Skudai

- Universiti Teknologi Malaysia (2014). Facts and Figures 2014. Malaysia. Retrieved June 22, 2015 from http://www.utm.my/

- UTM Annual Report (2012). Malaysia. Retrieved June 22, 2015 from http://www.utm.my/

- Venkataraman, S., MacMillan, I. C., \& McGrath, R. G. (1990). Progress in research on corporate venturing. Wharton School of the University of Pennsylvania, Snider Entrepreneurial Center.
- Wright, M., Hmieleski, K. M., Siegel, D. S., \& Ensley, M. D. (2007). The role of human capital in technological entrepreneurship. Entrepreneurship Theory and Practice, 31(6), 791-806, CrossRef

- Ziedonis, A. a. (2004). MIT and the Rise of Entrepreneurial Science. Research Policy, 33(1), 177-178, CrossRef 